\title{
Editorial
}

\section{A New Research Journal on Thermal Sciences: Thermo}

\author{
Johan Jacquemin ${ }^{1,2}$ (D)
}

1 Laboratoire PCM2E, Université de Tours, Parc de Grandmont, 37200 Tours, France; jj@univ-tours.fr

2 Materials Science and Nano-Engineering, Mohammed VI Polytechnic University, Lot 660-Hay Moulay

Citation: Jacquemin, J. A New Research Journal on Thermal Sciences: Thermo. Thermo 2021, 1, 61-62. https://doi.org/10.3390/ thermo1010005

Received: 20 March 2021

Accepted: 21 March 2021

Published: 6 April 2021

Publisher's Note: MDPI stays neutral with regard to jurisdictional claims in published maps and institutional affiliations.
Rachid, Ben Guerir 43150, Morocco

I am honored to take on the role of Editor-in-Chief of Thermo (ISSN 2673-7264) effective from February 2021. In brief, Thermo (ISSN 2673-7264) was recently created as an international peer-reviewed open access journal devoted to the publication of advanced studies on the thermal sciences in general. The first volume is scheduled to publish in June 2021 and this journal will then be published online quarterly by MDPI. Launching a novel journal is an enormous task that I accepted with humility, for which I will not only allocate my time, energy and enthusiasm but also utilize my passion for both research and the teaching of the aspects of thermodynamics. To be honest with you, this will be facilitated thanks to the hard work already done by the editorial office. However, as a sea captain cannot navigate alone, a sole editorial office cannot launch a journal without any help. The first 6 months were thus devoted to inviting top researchers, academics and scientists to take part to this adventure. To date, I really am glad that many leaders in the thermal sciences accepted our offer to join Thermo as editoral board members (EBM). Their brief profiles are available here: https:/ /www.mdpi.com/journal/thermo/editors (accessed on 30 March 2021). Our journal is now looking to further expand our editorial board to address the gaps present and further enrich the journal. To become an EBM or a referee for our journal, please email the Editor-in-Chief (jj@univ-tours.fr) or the office (thermo@mdpi.com), offering your expertise in any specific area(s) of the thermal sciences.

Our main tasks will be to satisfy authors, referees and readers by providing a fastprocessing time and a unique quality of service one can expect when submitting an original article. We also aim to: (i) offer easy access to high-quality research for a wide range of scientists; (ii) provide a unique platform for trainees, fellows and researchers in academia and the industry to disseminate their cutting-edge results; (iii) promote communication between researchers; and iv) connect theory with practice and exchange new innovationoriented research and concepts.

Thermo aims to publish high-impact fundamental research and applications from different branches of research that help to further enrich the discourse on the thermal sciences. More precisely, this new open access journal publishes original research papers, letters, reviews and special issues in all areas dealing with experimental, theoretical and applied thermal sciences. We deeply encourage scientists to publish their experimental and theoretical results in as much detail as possible, which explains why there is no restriction on the length of the papers submitted. Furthermore, papers dealing with good research and teaching practices either: (i) introducing theoretical or experimental methods; or (ii) dealing with equipment calibrations and measurement recommendations are also accepted to provide solid textbooks for undergraduate and postgraduate students.

On the one hand, the thermal sciences play a crucial role in today's life, especially when studying novel processes dealing with various aspects of heat and temperature. The field of opportunity is, in fact, vast, explaining why our journal warmly welcomes original papers based on the study of thermodynamics, statistical mechanics and kinetic theory. On the other hand, the design of novel applications depends on continuous innovation and technological development, which in turn requires a constant income of original, high-quality, accurate and reliable results. For that reason, our journal particularly accepts 


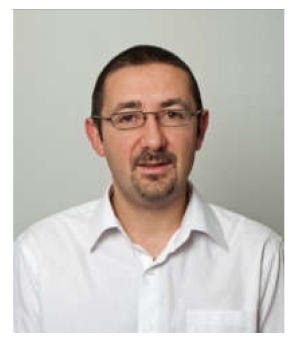

both theoretical (simulation) and/or experimental research papers within our journal's scope, also including satellite topics dealing with thermophysics, solubility phenomena, chemical thermodynamics and chemical engineering.

To date, four papers have already been accepted and are available online, and five special issues are now open, giving readers a taste of our philosophy and journal direction.

On behalf of the editorial board members, we are honored to present Thermo as a new and reliable open access journal with a strong and fast peer review process, and it is our pleasure to invite you as a reader of Thermo to share your latest findings by submitting original manuscripts and/or proposals for special issues.

In closing, as I do think that we need to work together as a community, I will greatly appreciate your advice and suggestions to enhance the reputation of the journal, which will doubtless contribute to promoting the knowledge development of the thermal sciences.

I look forward to working with all of you.

Conflicts of Interest: The author declares no conflict of interest.

\section{Short Biography of Author}

Dr. Jacquemin is Associate Professor in Thermodynamics at the School of Chemistry at Tours University (France). His current research interests are mainly devoted in applied sciences, thermodynamic and chemical engineering. He serves as Editor/Guest Editor for different journals for several journals and is an active member of the Subcommittee on Solubility and Equilibrium Data of the IUPAC. He was also involved numerous conferences including ILSEP, ISSP, Calcon, ACS National Meeting, IUPAC World Chemistry Congress, Thermal Analysis and Calorimetry as symposium/session chair and keynote speaker. The activities of his research team have led to the publication of more than 150 highly cited articles, 1 patent and 8 book chapters. 